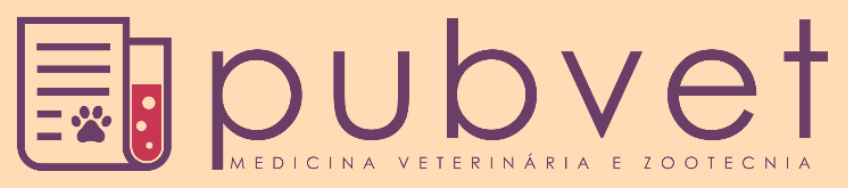

https://doi.org/10.31533/pubvet.v13n8a387.1-6

\title{
Perfil bioquímico sérico de gatos (Felis catus domesticus) domésticos submetidos ao consumo exclusivo de dieta seca ou dieta mista
}

\author{
Mara Luciana Silva Marques ${ }^{1}$, Joanna Jéssica Sousa Albuquerque ${ }^{2}{ }^{\circ}$, Leandro Macedo \\ Miranda $^{3}{ }^{\circ}$, Érika de Souza Paiva ${ }^{\circ}$, Mylena Andréa Oliveira Torres ${ }^{5}{ }^{\circ}$, Tiago da Silva \\ Teófilo $^{6}{ }^{\circ}$, Erlin Cely Cotrim Cavalcante ${ }^{\circ}{ }^{\circ}$, Daniel Praseres Chaves ${ }^{8}{ }^{\circ}$, Rudson Almeida de \\ Oliveira $^{8} \bullet$, Nathálya dos Santos Martins ${ }^{8 * \bullet}$ \\ ${ }^{I}$ Médica Veterinária pelo Programa de Aperfeiçoamento Técnico em Medicina Veterinária, São Luís, Maranhão, Brasil; \\ ${ }^{2}$ Médica Veterinária pelo Programa de Residência em área profissional da saúde - Anestesiologia Veterinária, Teresina, Piauí, Brasil; \\ ${ }^{3}$ Mestrando em Ciência Animal, São Luís, Maranhão, Brasil; \\ ${ }^{4}$ Médica veterinária da Universidade Federal do Piauí, Picos, Piauí, Brasil; \\ ${ }^{5}$ Professora do Centro Universitário do Maranhão, São Luís, Maranhão, Brasil; \\ ${ }^{6}$ Doutorando pelo programa de Pós-Graduação em Ciência Animal, Universidade Federal Rural do Semi-Árido (UFERSA), MossoróRN, Brasil; \\ ${ }^{7}$ Médica Veterinária do Laboratório Cernitas, São Luís, Maranhão, Brasil. \\ ${ }^{8}$ Professor (a) da Universidade Estadual do Maranhão, São Luís, Maranhão, Brasil. \\ *Autor para correspondência, E-mail: veterinariamartins@hotmail.com*
}

Resumo. Este trabalho teve como objetivo comparar o perfil bioquímico sérico de gatos (Felis catus domesticus) submetidos à dieta exclusivamente seca e alimentados com dieta mista (associação de ração seca com úmida). Foram avaliados oito gatos domésticos residentes na cidade de São Luís - MA, selecionados com base no tipo de dieta consumida (seca ou mista), determinando-se as concentrações séricas de ureia, creatinina, proteína sérica total e frações, glicose, colesterol, atividades séricas de ALT, AST e FA. Os resultados obtidos apresentaram diferenças estatisticamente significativas somente para ureia $(\mathrm{P}<0,05)$, podendo ser ou não resultante da influência da dieta. A utilização de alimentos úmidos como parte da alimentação dos felinos mostrou-se, portanto, uma boa estratégia para o equilíbrio orgânico desses animais, necessitando de um maior número amostral para determinar a real influência da dieta sobre os perfis bioquímicos, pois outros fatores podem ter influenciado os resultados observados.

Palavras chave: dieta, gatos, perfil bioquímico

\section{Serum biochemical profile of domestic cats (Felis catus domesticus) submitted to the exclusive consumption of dry or mixed diet}

\begin{abstract}
The objective of this study was to compare the serum biochemical profile of cats (Felis catus domesticus) submitted to a dry diet and fed a mixed diet (dry damp diet). Eight domestic cats residing in the São Luís city were selected, based on the type of diet consumed (dry or mixed), being determined the serum concentrations of urea, creatinine, total serum protein and fractions, glucose, cholesterol, activities serum levels of ALT, AST and FA. The results obtained showed statistically significant differences only for urea (P $<0.05$ ), which may or may not be the result of dietary influence. The use of moist food as part of the feline diet was therefore a good strategy for the organic balance of these animals, necessitating a larger sample number to determine the real influence of the diet on the biochemical profiles, since other factors may have influenced the observed results.
\end{abstract}

Keywords: diet, cats, biochemical profile 


\section{Perfil bioquímico sérico de gatos (Felis catus domesticus) domésticos sometidos al consumo exclusivo de dieta seca o dieta mixta}

Resumen. Este trabajo tuvo como objetivo comparar el perfil bioquímico sérico de gatos (Felis catus domesticus) sometidos a dieta exclusivamente seca y alimentados con dieta mixta (balanza de ración seca con húmeda). Se evaluaron ocho gatos domésticos residentes en la ciudad de São Luís - MA, seleccionados con base en el tipo de dieta consumida (seca o mixta), determinándose las concentraciones séricas de urea, creatinina, proteína sérica total y fracciones, glucosa, colesterol, actividades de la ALT, AST y FA. Los resultados obtenidos presentaron diferencias estadísticamente significativas sólo para urea $(\mathrm{P}<0,05)$, pudiendo ser o no resultante de la influencia de la dieta. La utilización de alimentos húmedos como parte de la alimentación de los felinos se muestra, por tanto, una buena estrategia para el equilibrio orgánico de estos animales, necesitando un mayor número de muestras para determinar la real influencia de la dieta sobre los perfiles bioquímicos, otros factores pueden influir en los resultados observados.

Palabras clave: dieta, gatos, perfil bioquímico

\section{Introdução}

Felinos domésticos apresentam particularidades comportamentais e fisiológicas muito específicas, necessitando de nutrientes provenientes de tecidos de origem animal, cuja composição atende aos requisitos básicos de sua dieta, contendo altos teores de proteína e água, moderados teores de gordura e mínimos de carboidratos (Gandjean, 2010). Alimentos úmidos industrializados possuem características que os aproximam dos alimentos instintivamente preferíveis aos felinos. No entanto, rações industrializadas na forma seca, atualmente, constituem a dieta mais comum entre felinos domésticos (Case et al., 2011).

Muitos fatores têm contribuído para incidência de distúrbios metabólicos em felinos, dentre os quais estão os dietéticos. Cada nutriente da alimentação desempenha um papel específico, sendo que o excesso e a carência são considerados prejudiciais para a saúde do gato (Dibartola \& Rogers, 2004). Portanto, o tipo de dieta, ingredientes utilizados em sua formulação e a frequência com a qual é ofertada ao animal, são fatores importantes para manutenção e equilíbrio orgânico, podendo interferir, no metabolismo do animal, resultando em síndromes clínicas e consequências metabólicas diversas (Kirk et al., 2000). Considerando as particularidades dos felinos, a formulação das rações industrializadas deve levar em consideração suas exigências nutricionais e atender requisitos de sua alimentação básica, composta principalmente por proteínas, minerais, vitaminas, gorduras, água e baixos níveis de carboidratos (Case et al., 2011).

Considerando as características comportamentais dos felinos, as necessidades nutricionais sem um controle adequado de consumo e a falta de associação a alimentos úmidos, torna-se relevante avaliar as consequências desta condição dietética a partir do perfil bioquímico sérico desses animais.

\section{Material e métodos}

O estudo foi realizado com oito felinos domésticos (Felis catus domesticus) selecionados com base no tipo de dieta consumido (dieta seca ou mista), adultos, independente de raça, sexo, idade e modo de vida. Todos os animais apresentavam-se clinicamente sadios, não faziam uso de medicamentos e conviviam com seus tutores.

Os animais foram distribuídos de acordo com sua alimentação em dois grupos, o primeiro (G1), composto por quatro animais submetidos à dieta seca e o segundo (G2), com quatro animais submetidos a dieta mista (associação de ração seca e úmida).

Os elementos componentes da amostra foram baseados a partir de consultas da rotina no Hospital Veterinário Universitário da Universidade Estadual do Maranhão (UEMA) e visitas em domicílio, na cidade de São Luís - Maranhão. A presente pesquisa foi submetida ao Comitê de Ética e Experimentação 
Animal do Curso de Medicina Veterinária da Universidade Estadual do Maranhão - UEMA, sob protocolo 041/2014.

A inclusão dos animais estudados foi autorizada pelos tutores via termo de consentimento livre e esclarecido. Aplicaram-se questionários aos proprietários e a partir deste, obteve-se informações referentes ao tutor, ao animal, sua situação clínico e histórico de doenças metabólicas, assegurando, sobretudo, o tipo de dieta utilizada: ração exclusivamente seca ou ração mista.

Foram coletados $2 \mathrm{~mL}$ de sangue de cada animal por meio da punção da veia jugular externa, utilizando-se tubos tipo "vacutainer" estéreis, sem anticoagulante, acoplado a agulha 25 x $0,8 \mathrm{~mm}$. Em seguida, armazenaram-se as amostras em geladeira até momento da centrifugação. As amostras foram centrifugadas a 3000 r.p.m, durante 5 minutos para separação e extração de soro.

Após centrifugação das amostras de soro sanguíneo, realizada em um Laboratório particular (Cernitas), foram determinadas as concentrações séricas de ureia, creatinina, proteína sérica total, albumina, globulinas, atividades séricas de alanina Aminotransferase (ALT), Aspartato Aminotransferase (AST) e Fosfatase Alcalina (FA), e ainda, glicose e colesterol. Foram utilizados Kits bioquímicos veterinários específicos $\left(\right.$ Labtest $\left.^{\circledR}\right)$, seguindo recomendações do fabricante e a leitura foi realizada em analisador bioquímico semiautomático (Bio 2000-Bioplus) (Kaneko et al., 2008).

Após tabulados e compactados, os dados foram apresentados em forma de tabelas, conforme a variável observada. Procedeu-se com análise de variância (ANOVA) expressando as médias das variáveis do perfil bioquímico (Ureia, Creatinina, Fosfatase Alcalina, Albumina, Globulinas, Proteína sérica total, AST e ALT, Glicose e Colesterol) com subsequente comparação das médias dos grupos de animais alimentados com dieta seca e mista, pelo teste t pareado.

As análises foram realizadas utilizando o pacote estatístico GraphPadInstat versão 3.05. Todas as análises estatísticas foram realizadas considerando-se um nível de significância mínima de 5\%.

\section{Resultados e discussão}

De acordo com os dados obtidos nos questionários aplicados aos proprietários dos animais do Grupo I (submetidos à dieta seca) e do Grupo II (submetidos a dieta mista), todos os animais apresentavam-se clinicamente sadios, sem histórico de doenças metabólicas ou uso de medicamentos, não tinham acesso à rua e mantinham modo de vida sedentário. A oferta de água, para todos os animais, era realizada por meio de vasilhas posicionadas ao lado dos comedouros.

Para os animais do Grupo I, o esquema de alimentação à vontade (ad libitum), era utilizado por todos os proprietários questionados. Todos os animais do Grupo II alimentavam-se de ração seca (oferecidas de quatro a oito vezes ao dia) e úmida (uma a três vezes ao dia).

A Tabela 1 apresenta os resultados obtidos para o perfil bioquímico sérico dos animais do grupo I seguidos da média para cada parâmetro bioquímico dosado (ureia, creatinina, proteínas totais, albumina, globulina, AST, ALT, FA, glicose e colesterol). Os valores médios das concentrações séricas de creatinina, proteínas totais, albumina, globulina, FA, glicose e colesterol apresentaram-se conforme os intervalos referenciados por Kaneco et al. (1997). As médias da uréia, AST e ALT, apresentaram-se elevadas, quando comparadas aos valores de referência.

Os resultados obtidos para os parâmetros bioquímicos dos animais do Grupo II (submetidos a dieta mista) e respectivas médias, estão dispostos na Tabela 2. Para este grupo, todos os parâmetros, com exceção de ALT, apresentaram valores médios dentro dos padrões de normalidade, seguindo mesmos intervalos referenciais do Grupo I.

Entretanto, quando analisados individualmente, os animais do Grupo I, representados na Tabela 1, apresentaram alterações nos níveis séricos de colesterol, com evidente elevação deste parâmetro para dois dos quatro animais estudados (Animal I e IV com 173,00 e 151,00 mg/dL, respectivamente).

Considerando que todos os animais deste grupo, apresentavam-se clinicamente sadios, sem histórico de doenças metabólicas, com modo de vida sedentário e, ainda, adeptos ao esquema de alimentação ad libitum, onde não são devido controle de consumo favorecendo excesso de ingestão, essa elevação no nível sérico de colesterol dos Animais I e IV, pode ser indicativo de anormalidades no metabolismo 
energético, sendo fator de risco para obesidade em felinos (Hoenig et al., 2008). Segundo mesmo autor, na espécie felina, a obesidade predispõe ao aumento dos níveis de TGL, diminuição dos níveis de HDL e aumento dos nineis de LDL assim como o aumento do colesterol.

Tabela 1. Perfil bioquímico sérico de gatos domésticos submetidos ao consumo exclusivo de ração seca. São Luís - MA, 2016

\begin{tabular}{lcccccc}
\hline Parâmetros bioquímicos & Animal I & Animal II & Animal III & Animal IV & Média & Valores de Referência \\
\hline Ureia, mg/dL, & 59,00 & 78,00 & 65,00 & 69,50 & 67,88 & $42,80-64,20$ \\
Creatinina, mg/dL, & 1,20 & 0,80 & 0,90 & 1,60 & 1,13 & $0,50-1,80$ \\
Proteínas totais, g/dL & 5,51 & 6,50 & 5,37 & 9,20 & 6,65 & $5,80-7,90$ \\
Albumina, g/dL & 1,60 & 3,90 & 4,10 & 3,90 & 3,38 & $1,90-3,80$ \\
Globulina, g/dL & 3,90 & 2,60 & 1,27 & 5,30 & 3,27 & $2,60-5,10$ \\
AST, UI/L & 73,30 & 31,40 & 83,80 & 68,00 & 64,13 & $9,20-39,50$ \\
ALT, UI/L & 72,00 & 41,00 & 77,00 & 68,00 & 64,50 & $<50,00$ \\
FA, UI/L & 10,00 & 13,00 & 10,80 & 25,00 & 14,70 & $12,00-65,10$ \\
Glicose, mg/dL & 88,80 & 88,80 & 78,30 & 91,90 & 89,18 & $73,00-134,00$ \\
Colesterol, mg/dL & 173,00 & 87,00 & 97,00 & 151,00 & 127,00 & $95,00-130,00$
\end{tabular}

AST $=$ Aspartato Aminotransferase ALT = Alanino Aminotransferase $;$ FA = FosfataseAlcalina

Segundo Fleeman et al. (2006), fatores relacionados com dieta, tais como o método e o tipo de alimentação podem ter influência na predisposição da obesidade felina e consequente aumento de colesterol sérico. Evidenciando tais afirmações, nesta pesquisa, observou-se expressiva diferença entre as médias de colesterol sérico para os dois tipos de dietas estudadas. O grupo de animais alimentados com ração mista (Grupo II), apresentou média de 100,95 mg/dL; enquanto que, o grupo dos animais alimentados exclusivamente com ração seca (Grupo II), obteve média de 127,00 mg/dL.

Todos os animais do Grupo II, cujos componentes são alimentados com associação de ração seca e úmida de modo intermitentemente, apresentaram níveis de colesterol sanguíneo dentro dos intervalos de referência, como pode ser observado na Tabela 2. Esses resultados indicam correlação entre o método de alimentação e tipo de dieta com os níveis de colesterol plasmático. Essa correlação confirma, ainda, resultados encontrados por Meyer et al. (2001), Stockham \& Scott (2011) e Hoenig et al. (2008). Como consequência do elevado nível sérico da ureia em três dos animais do Grupo I, o valor médio para esse parâmetro, também se apresentou elevado $(67,88 \mathrm{mg} / \mathrm{dL})$. Em contrapartida, os animais do Grupo II, apresentaram média dos valores de ureia sérica $(55,30 \mathrm{mg} / \mathrm{dL})$ conforme intervalo referenciado.

Tabela 2. Perfil bioquímico sérico de gatos domésticos submetidos ao consumo de dieta mista (associação de ração seca com ração úmida). São Luís- MA, 2016

\begin{tabular}{lcccccc}
\hline Parâmetros Bioquímicos & Animal I & Animal II & Animal III & Animal IV & Média & Valores de Referência \\
\hline Ureia, mg/dL, & 55,00 & 62,20 & 53,00 & 51,00 & 55,30 & $42,80-64,20$ \\
Creatinina, mg/dL, & 0,80 & 0,80 & 0,60 & 1,20 & 0,85 & $0,50-1,80$ \\
Proteínas totais, g/dL, & 6,90 & 7,60 & 7,20 & 6,90 & 7,15 & $5,80-7,90$ \\
Albumina, g/dL & 3,60 & 3,70 & 3,70 & 2,70 & 3,38 & $1,90-3,80$ \\
Globulina, g/dL & 3,30 & 3,90 & 3,50 & 4,20 & 3,73 & $2,60-5,10$ \\
AST, UI/L & 39,20 & 40,00 & 30,20 & 28,00 & 34,35 & $9,20-39,50$ \\
ALT, UI/L & 52,00 & 48,00 & 61,80 & 51,60 & 53,35 & $<50,00$ \\
FA, UI/L & 13,00 & 19,00 & 13,30 & 17,30 & 15,65 & $12,00-65,10$ \\
Glicose, mg/dL & 88,50 & 77,00 & 79,00 & 79,00 & 81,08 & $73,00-134,00$ \\
Colesterol, mg/dL & 98,00 & 103,00 & 96,80 & 106,00 & 100,95 & $95,00-130,00$ \\
Ureia, mg/dL, & 55,00 & 62,20 & 53,00 & 51,00 & 55,30 & $42,80-64,20$ \\
\hline
\end{tabular}

AST = Aspartato Aminotransferase; ALT = Alanino Aminotransferase; FA = Fosfatase Alcalina

A Tabela 3 apresenta as análises estatísticas descritivas (média e desvio padrão) com subsequente comparação das médias dos grupos de animais alimentados com dieta seca e mista, pelo teste t pareado. Os resultados, de acordo com o tipo de dieta consumida, apresentaram diferenças para ureia $(\mathrm{P}<0,05)$, demonstrando possível influência da dieta sobre sua dosagem sérica. 
Entre outros fatores, a elevação da ureia sérica nos animais alimentados com ração seca (Grupo I), pode estar associada ao grau de hidratação do animal. Segundo Kirk et al. (2000), gatos submetidos a dieta seca, devem ingerir maior quantidade de água potável para atingir seu requerimento mínimo de líquido, entretanto, por seu menor estímulo de sede e resistência na manifestação dos sinais de desidratação, esta espécie necessita de constante intervenção do proprietário para incentivar a ingestão de água, o que não ocorre em 100\% dos casos estudados nesta pesquisa.

Tabela 3. Valores médios e respectivos desvios-padrão das variáveis dos parâmetros bioquímicos das amostras de felinos, provenientes do município de São Luís - MA, comparando-se animais com alimentação seca e mista. São Luís, 2016

\begin{tabular}{|c|c|c|c|c|c|c|c|}
\hline \multirow{2}{*}{ Parâmetros Bioquímicos } & \multicolumn{2}{|c|}{ Dieta Seca } & \multicolumn{2}{|c|}{ Dieta Mista } & \multirow{2}{*}{$\begin{array}{l}\text { Valores de } \\
\text { Referência }\end{array}$} & \multirow{2}{*}{ Teste $\mathrm{t}$} & \multirow{2}{*}{ Valor $\mathrm{p}$} \\
\hline & Média & DP & Média & $\mathrm{DP}$ & & & \\
\hline Ureia, mg/dL, & $67.88 \mathrm{a}$ & \pm 8.007 & $55.30 \mathrm{~b}$ & \pm 4.881 & $42,80-64,20$ & 3.987 & 0.0282 \\
\hline Creatinina, $\mathrm{mg} / \mathrm{dL}$, & $1.13 \mathrm{a}$ & \pm 0.3594 & $0.85 \mathrm{a}$ & \pm 0.2517 & $0,50-1,80$ & 2.905 & 0.0622 \\
\hline Proteínas totais, $\mathrm{g} / \mathrm{dL}$, & $6.65 \mathrm{a}$ & \pm 1.776 & $7.15 \mathrm{a}$ & \pm 0.3317 & $5,80-7,90$ & 0.5333 & 0.6308 \\
\hline Albumina, g/dL, & $3.43 \mathrm{a}$ & \pm 0.4856 & $3.38 \mathrm{a}$ & \pm 1.187 & $1,90-3,80$ & 0.07300 & 0.9464 \\
\hline Globulina, g/dL, & $3.27 \mathrm{a}$ & \pm 1.729 & $3.73 \mathrm{a}$ & \pm 0.4031 & $2,60-5,10$ & 0.5828 & 0.6010 \\
\hline AST, UI/L, & $64.13 \mathrm{a}$ & \pm 22.783 & $34.35 \mathrm{a}$ & \pm 6.137 & $9,20-39,50$ & 2.217 & 0.1133 \\
\hline ALT, UI/L, & $64.50 \mathrm{a}$ & \pm 16.093 & $53.35 \mathrm{a}$ & \pm 5.914 & $<50,00$ & 1.817 & 0.1668 \\
\hline Fosfatase alcalina, UI/L & $14.70 \mathrm{a}$ & \pm 6.983 & $15.65 \mathrm{a}$ & \pm 2.972 & $12,00-65,10$ & 0.3182 & 0.7712 \\
\hline Glicose, $\mathrm{mg} / \mathrm{dL}$ & $89.18 \mathrm{a}$ & \pm 8.134 & $81.08 \mathrm{a}$ & \pm 5.088 & $73,00-134,00$ & 1.533 & 0.2227 \\
\hline Colesterol, mg/dL, & $127.00 \mathrm{a}$ & \pm 41.601 & $100.95 \mathrm{a}$ & \pm 4.306 & $95,00-130,00$ & 1.252 & 0.2992 \\
\hline
\end{tabular}

a - Letras iguais na mesma linha indicam não haver diferenças entre as médias (P > 0,05). b - letras diferentes na mesma linha indicam haver diferenças estatísticas significativas entre as médias $(\mathrm{P}<0,05) .1$ - ANOVA com comparação das médias pelo teste t paramétrico. AST = Aspartato Aminotransferase; ALT = Alanino Aminotransferase; DP = Desvio Padrão.

De acordo com Núñez \& Bouda (2007), a diminuição da quantidade da urina ocasionada por desidratação, facilita a reabsorção de ureia, com consequente aumento de seu nível sérico. A elevação desse parâmetro bioquímico nos animais do Grupo I pode estar associada, ainda, a ingestão excessiva de proteínas, pois, segundo Meyer et al. (2001), o nível de ureia aumenta na mesma proporção em que aumenta o consumo de proteínas na dieta. Considerando que há evidências de maior teor proteico na ração úmida, quando comparada à ração seca, a elevação dos níveis séricos de ureia, neste caso, pode ser resultado da ingestão abusiva de alimento, o que pode ser explicado pelo esquema de alimentação à vontade, empregada para os animais deste grupo.

Os resultados não demonstraram diferenças estatisticamente significativas para os valores de creatinina, proteínas totais, albumina, globulina, AST, ALT, FA, glicose e colesterol, como demonstra a Tabela 3, verificando que não houve influência estatística da dieta sobre as dosagens séricas desses parâmetros, apesar das variações individuais para os animais de cada grupo, observadas na Tabela 1 e na Tabela 2, indicarem alterações que podem representar fatores de risco para ocorrência de distúrbios metabólicos.

\section{Referências bibliográficas}

Case, L. P., Daristotle, L., Hayek, M. G. \& Raasch, M. F. (2011). Canine and feline nutrition. Estados Unidos: Elsevier.

Dibartola, J. C. \& Rogers, Q. R. (2004). Evaluation of commercial pet food. Journal American Medical Association, 192676-680.

Fleeman, L. M., Seton, E. J. \& Rand, J. (2006). Como abordar: O manejo da obesidade em cães e gatos. Veterinary Focus, 169-15.

Gandjean, D. (2010). Tudo o que você deve saber sobre nutrientes para saúde de cães e gatos. Paris, France: Edn. Aniwa.

Hoenig, M., Caffall, Z. \& Ferguson, D. C. (2008). Triiodothyronine differentially regulates key metabolic factors in lean and obese cats. Domestic Animal Endocrinology, 34(3):229-237.

Kaneco et al. (1997). 
Kaneko, J. J., Harvey, J. W. \& Bruss, M. L. (2008). Clinical biochemistry of domestic animals (Vol. 1). New York: Academic press.

Kirk, C. A., Debwekeler, J. \& Armstrong, P. J. (2000). Normal cats. In H. M. S., T. C. D., R. L. Remillard \& P. Roundebush (Eds.), Small animal clinical nutrition. Missouri, USA: Walsworth Publishing Company.

Meyer, D. J., Coles, E. H., J.R., L. \& Oliveira, P. M. (2001). Medicina de laboratório veterinária: interpretação e diagnóstico. São Paulo: Roca.

Núñez, O. L. \& Bouda, J. (2007). Patología Clínica Veterinaria (Vol. 1. ed). Mexico: FMVZ-UNAM.

Stockham, S. L. \& Scott, M. A. (2011). Fundamentos de patologia clínica veterinária (Vol. 8). Rio de Janeiro.

Recebido: 11 de junho, 2019.

Aprovado: 10 de julho, 2019.

Publicado: 3 de setembro, 2019.

Licenciamento: Este artigo é publicado na modalidade Acesso Aberto sob a licença Creative Commons Atribuição 4.0 (CC-BY 4.0), a qual permite uso irrestrito, distribuição, reprodução em qualquer meio, desde que o autor e a fonte sejam devidamente creditadoo. 